\title{
Cytogenetic characterization of Diachasmimorpha longicaudata (Hymenoptera: Braconidae), a parasitoid wasp used as a biological control agent
}

\author{
Leonela CARABAJAL PALADiNO ${ }^{1,2}$, Alba PAPESCHI ${ }^{2}$, Silvia LANZAVECCHIA ${ }^{1}$, Jorge CLADERA ${ }^{1}$ \\ and MARÍA JosÉ BRESSA ${ }^{2}$ \\ ${ }^{1}$ Laboratorio de Genética de Insectos de Importancia Económica, Instituto de Genética "Ewald A. Favret”, Instituto Nacional de \\ Tecnología Agropecuaria (INTA-Castelar), Buenos Aires, Argentina; e-mails: leonela.carabajal@gmail.com; \\ slanzavecchia@cnia.inta.gov.ar; jcladera@cnia.inta.gov.ar \\ ${ }^{2}$ Instituto de Ecología, Genética y Evolución de Buenos Aires, Departamento de Genética y Evolución, Facultad de Ciencias Exactas \\ y Naturales, Universidad de Buenos Aires, Ciudad Autónoma de Buenos Aires, Argentina; e-mails: alpape@ege.fcen.uba.ar; \\ mjbressa@ege.fcen.uba.ar
}

Key words. Hymenoptera, Braconidae, Diachasmimorpha longicaudata, karyotype, C-banding, heterochromatin, Ag-NOR, FISH, rDNA

\begin{abstract}
Diachasmimorpha longicaudata (Hymenoptera: Braconidae) is a parasitoid wasp widely used in the biological control of fruit flies. In this paper, we present a detailed analysis of the karyotype of this species based on the results of classical and molecular cytogenetic techniques. The cytogenetic analysis confirmed the male and female chromosome numbers previously reported $(\mathrm{n}=$ $20,2 n=40$ ). The entire short arm of most chromosomes is made up of a large constitutive heterochromatic segment. The high heterochromatin content differentiates $D$. longicaudata from other braconid species. Fluorescence in situ hybridization (FISH) using autologous 18S rDNA probes revealed six clusters of rDNA, i.e. six nucleolar organizer regions (NORs), in the heterochromatic short arms of different chromosomes in the haploid male karyotype. This number is exceptionally high for Hymenoptera, which usually have two NORs in the diploid complement. It is noteworthy that these rDNA-FISH experiments represent the first use of this technique on a braconid species using autologous probes. Since Ag-NOR-bands were coincident with C-positive bands on metaphase chromosomes, it was not possible to identify active nucleoli. The physical characteristics of the D. longicaudata karyotype, especially the content and distribution of heterochromatin and the number and location of rDNA clusters, contribute to a better understanding of the structure and organization of braconid chromosomes and provide a basis for genomic and evolutionary studies.
\end{abstract}

\section{INTRODUCTION}

Parasitic Hymenoptera constitute one of the most taxonomically complex groups of insects (Rasnitsyn, 1980; Quicke, 1997). Even though they are economically important as biological control agents of agricultural and forestry pests (Viktorov, 1976; Godfray, 1994), their chromosomes remain poorly studied (Gokhman, 2004). Karyological research is often incorporated into molecular studies on parasitic wasps, namely that on entomopathogenic viruses associated with many species of this group (Stoltz \& Whitfield, 1992; Belle et al., 2002), the analysis of sex determination (Whiting \& Whiting, 1925; De Menten et al., 2003,) and the mapping of particular genes (Matsumoto et al., 2002). However, in order to render the chromosomes recognizable, the karyotype of the species must be examined in detail prior to molecular studies. Hymenoptera that are held in laboratory stocks may represent useful models for karyotaxonomic research and chromosome analyses, since their easy availability facilitates the interpretation of differences in the karyological characters (Gokhman, 2000a).

The haploid chromosome number of the more than 400 species of parasitic wasps studied up to now varies from 3 to 23 (Gokhman, 2009). The lowest number is found in Aphidius sp. (Nees) (Braconidae), Encarsia protransvena (Viggiani) (Aphelinidae), Brachymeria intermedia (Nees)
(Chalcididae) and Perilampus ruschkai (Hellen) (Perilampidae) (Hung, 1986; Quicke, 1997; Baldanza et al., 1999; Gokhman, 2000a, 2005), and the highest number in Fopius arisanus (Sonan) (Braconidae) (Kitthawee et al., 2004). According to this character, the distribution of the species is bimodal with two distinct peaks at $n=6$ and $n$ $=11$ (Gokhman, 2003, 2004, 2006). Similar modal numbers $(n=6$ and $n=10)$ are recorded if chromosome numbers are counted at the genus level (Gokhman \& Quicke, 1995; Gokhman, 2000b, 2003, 2005). With regard to their morphology, the chromosomes of parasitoid wasps are monocentric and biarmed, except in some species of Ichneumonidae that have acrocentric chromosomes (Abe, 1994; Gokhman, 2001, 2003, 2004). Therefore, this group characteristically has symmetric karyotypes (Stebbins, 1950). The chromosomes range in size from 12-15 to $0.5-1 \mu \mathrm{m}$, with most of them of medium size $(3-5 \mu \mathrm{m})$ (Crozier, 1975; Gokhman, 2003). Chromosomes of most parasitic Hymenoptera gradually decrease in size, and the largest and the smallest usually differ in length by no more than 2-2.5 times. However, important differences in size of single chromosomes are recorded for some species of Braconidae, Ichneumonidae, Drynidae, Eulophidae and Torymidae (Gokhman, 2001, 2002, 2009).

The relatively few reports of the distribution of heterochromatin reveal that the chromosomes usually have dis- 
tinct pericentromeric and telomeric heterochromatic segments (Hoshiba \& Imai, 1993; Reed, 1993; Gokhman, 1997; Baldanza et al., 1999; Gokhman \& Westendorf, 2000, 2003). Segments of intercalary position are rare and only described for some Ichneumonidae and Aphelinidae (Gokhman, 1997; Baldanza et al., 1999). Imai et al. (1988) proposed the term "pseudoacrocentric" for those chromosomes with the short arm fully heterochromatic and the long one euchromatic. This type of chromosomes is relatively frequent in parasitic wasps (Gokhman, 1985, 1997; Hoshiba \& Imai, 1993; Baldanza et al., 1999; Gokhman \& Westendorf, 2000), except in Aphidius ervi (Haliday) $(2 \mathrm{n}=12)$ in which some chromosomes are entirely heterochromatic. The ribosomal genes can be studied by the conventional silver staining technique (AgNOR), which reveals functional nucleolar organizer regions (NORs), and by fluorescence in situ hybridization (FISH) with specific ribosomal DNA (rDNA) probes, which accurately locate ribosomal genes (Sumner, 1990). Using Ag-NOR NOR regions have been located on both homologous chromosomes in a few wasps of the families Aphelinidae, Eulophidae and Pteromalidae (Reed, 1993; Baldanza et al., 1999; Maffei et al., 2001; Giorgini \& Baldanza, 2004; Bernardo et al., 2008). On the other hand, in four species of the genus Encarsia with the same chromosome number, this region is located on different chromosomes (Baldanza et al., 1999; Baldanza \& Giorgini, 2001; Giorgini \& Baldanza, 2004). Up to now, the chromosomal location of rDNA has only been identified in the karyotypes of two parasitic wasps, Trichogramma kaykai (Pinto \& Stouthamer) (Trichogrammatidae) (Van Vugt et al., 2009) and Cotesia congregata (Say) (Braconidae) (Belle et al., 2002) using FISH with $45 \mathrm{~S}$ rDNA heterologous probes prepared from wheat and Drosophila melanogaster (Linnaeus).

Diachasmimorpha longicaudata (Ashmead) (Ichneumonoidea, Braconidae, Opiinae) is a hymenopteran parasitoid that is easy to rear under artificial conditions using fruit flies as hosts (Marucci \& Clancy, 1950). It is a native of Southeast Asia and was introduced into America as a biological control agent of tephritid fruit flies, which are very important pests of fruit worldwide (Sivinski, 1996). So far, only specimens of $D$. longicaudata from central Thailand have been cytogenetically examined. Reported data indicate that this species has $2 \mathrm{n}=40$ chromosomes in females and $n=20$ chromosomes in males (Kitthawee et al., 1999). As a result of the haplodiploid sex determination system characteristic of Hymenoptera, females are diploid and males haploid. A detailed description of the D. longicaudata karyotype will provide a tool for better identification of its chromosomes and also facilitate the location of chromosome markers for constructing a genetic map of this species. In addition, this species could also be used as a model organism to develop and improve cytological techniques that could then be applied to other parasitoid species, which are difficult to rear in the laboratory but can be collected in the field.
In the present work, we analyzed the male and female karyotypes of D. longicaudata and mapped the distribution of constitutive heterochromatin in relation to karyotype differentiation. We also determined the number and location of NORs by means of Ag-NOR staining and FISH using 18S rDNA autologous probes. Our cytogenetic findings provide a deeper knowledge of chromatin organization and constitution of the chromosomes in parasitic Hymenoptera. In addition, they provide information interesting for the use of $D$. longicaudata as biological control agent.

\section{MATERIAL AND METHODS}

\section{Experimental insects}

Diachasmimorpha longicaudata individuals were imported from Mexico to Tucumán province (Argentina) in 1998 and cultured in our laboratory (Buenos Aires province, Argentina) since 2001 (SENASA, $\mathrm{n}^{\circ}$ 14054/98). They are reared on Ceratitis capitata (Wiedemann) larvae and kept in an incubator at $25^{\circ} \mathrm{C}, 85 \%$ relative humidity and $18 \mathrm{~L}: 6 \mathrm{D}$ photoperiod. In order to obtain individuals of a particular stage this parasitoid was reared using the method described by Carabajal Paladino et al. (2010).

\section{Chromosome preparations}

Preparations were made following two different protocols, depending on the nature of the subsequent analysis. For classical cytogenetic analysis, the preparations were made using the squash technique following the protocol of Guerra (1999), with slight modifications. Briefly, the gonads of male and female prepupae and pharate adult parasitoids were dissected in a physiological solution developed for Ephestia (Glaser, 1917 cited in Lockwood, 1961), swollen for $5 \mathrm{~min}$ in a hypotonic solution $(0.075 \mathrm{M} \mathrm{KCl})$, fixed for $30 \mathrm{~min}$ in freshly prepared fixative solution (ethanol, acetic acid, $3: 1$ ) and then stained with $2 \%$ haematoxylin with iron alum for $30 \mathrm{~min}$. The gonads were then washed five times with distilled water and transferred into a drop of $45 \%$ acetic acid on a slide. After squashing, the preparations were sealed with nail varnish.

For banding and FISH, chromosome preparations were made by spreading testes and ovaries from pupae and pharate adults of the parasitoid, according to Traut (1976) with slight modifications detailed in Bressa et al. (2009). The preparations were then dehydrated in an ethanol series $(70 \%, 80 \%$, and $96 \%, 30 \mathrm{~s}$ each) and stored until further use either at room temperature for chromosome banding or at $-20^{\circ} \mathrm{C}$ for FISH.

\section{C-banding}

C-banding was performed according to Papeschi (1988) with the aim of analyzing the content and distribution of constitutive heterochromatin. For a better resolution of C-bands the chromosome preparations were stained with $0.5 \mu \mathrm{g} / \mathrm{ml}$ DAPI (SigmaAldrich, Buchs, Switzerland). The preparations were mounted in $30 \mu 1$ of antifade based on DABCO (Sigma-Aldrich) (for composition see Traut et al., 1999), each covered with a $24 \times 40 \mathrm{~mm}$ cover glass and sealed with clear nail polish. A total of ten male and ten female individuals were analyzed. From two to ten cells at pachytene (females) and metaphase stages (females and males) per individual were photographed and counted.

\section{Ag-NOR staining}

Ag-NOR staining was performed according to Stack et al. (1991) with the following modifications: $50 \mu \mathrm{l}$ of aqueous silver nitrate solution $(25 \% \mathrm{w} / \mathrm{v}$ in distilled water $\mathrm{pH} 3)$ were placed on a slide and covered with nylon cloth (purchased at a fabric 

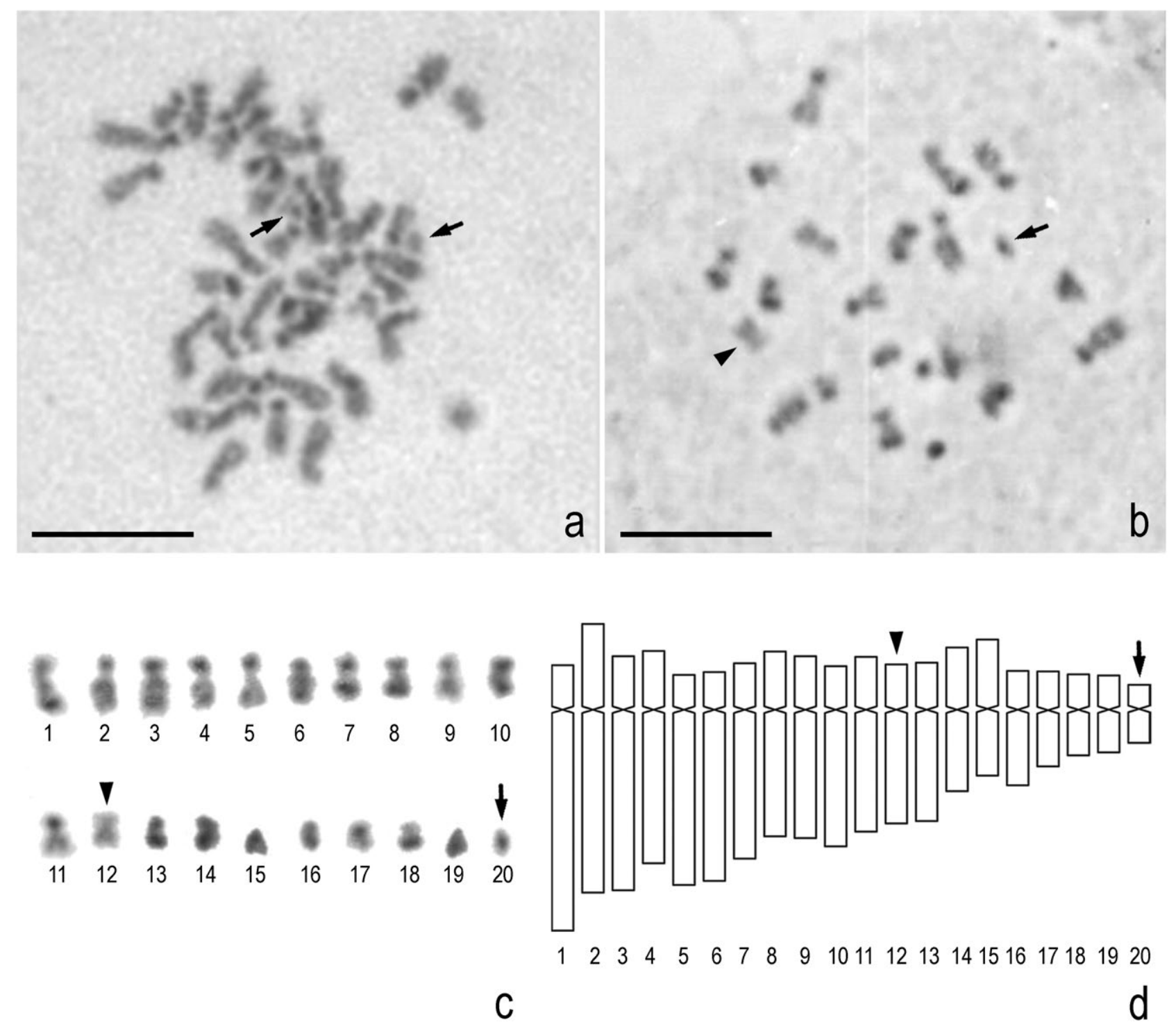

Fig. 1. Chromosome squash preparations of cells from prepupal individuals stained with haematoxylin with iron alum. a - cell at metaphase from ovaries; $\mathrm{b}$ - cell at metaphase from testes; $\mathrm{c}$ - male karyotype; $\mathrm{d}$ - ideogram of the male karyotype. Arrows, smallest chromosome of the complement (chromosome 20); arrowheads, negative heteropycnotic chromosome (chromosome 12). $\mathrm{Bar}=5 \mu \mathrm{m}$.

store). The slides were then incubated at $60^{\circ} \mathrm{C}$ for $50 \mathrm{~min}$ in a water bath. Afterwards, the nylon screens were washed off by shaking the slides vigorously in distilled water. Once air dried, preparations were made permanent using DPX mountant for histology (Sigma-Aldrich). Chromosome preparations were prepared for ten males, and spermatids, spermatocytes and metaphases were photographed and analyzed.

\section{Fluorescence in situ hybridization with rDNA probes}

Unlabelled 18S rDNA autologous probes were generated by polymerase chain reaction (PCR) using primers $18 \mathrm{~S}$ Gal forward 5'-CGATACCGCGAATGGCTCAATA-3' and 18S Gal reverse 5'-ACAAAGGGCAGGGACGTAATCAAC-3' (Fuková et al., 2005). PCR was done in a Mastercycler ${ }^{\circledR}$ Gradient Eppendorf thermal cycler (Eppendorf AG, Hamburg, Germany). Reactions were carried out with total genomic DNA as template, extracted from $D$. longicaudata adults by standard procedure according to Baruffi et al. (1995). The PCR product showed a single band of about $1000 \mathrm{bp}$ on a $1.5 \% \mathrm{w} / \mathrm{v}$ agarose gel. This band was recovered from the gel and purified using Wizard SV gel and PCR-clean up (Promega, Biodynamics S.R.L., Buenos Aires, Argentina). The rDNA probe was labelled by nick translation with biotin 14-dUTP (BioNick Labeling System, Invitrogen Life Technologies Inc., Buenos Aires, Argentina).

FISH using a biotinylated probe was carried out as described by Sahara et al. (1999) with several modifications as described by Fuková et al. (2005) and Bressa et al. (2009). Hybridization signals were detected using streptavidin-Cy3 conjugate (Jackson ImmunoRes. Labs. Inc., West Grove, PA, USA). The preparations were counterstained with $0.5 \mu \mathrm{g} / \mathrm{ml}$ DAPI in PBS containing 1\% Triton X-100 and mounted in Vectashield Mounting Medium (Vector Laboratories, Burlingame, CA, USA). A total of nine males and four females were analyzed. Between three to seven metaphases per individual were photographed and studied. In females, chromosomes at pachytene were also analyzed.

\section{Microscope and image processing}

The preparations were observed under an epifluorescent microscope Leica DMLB equipped with a Leica DFC350FX 

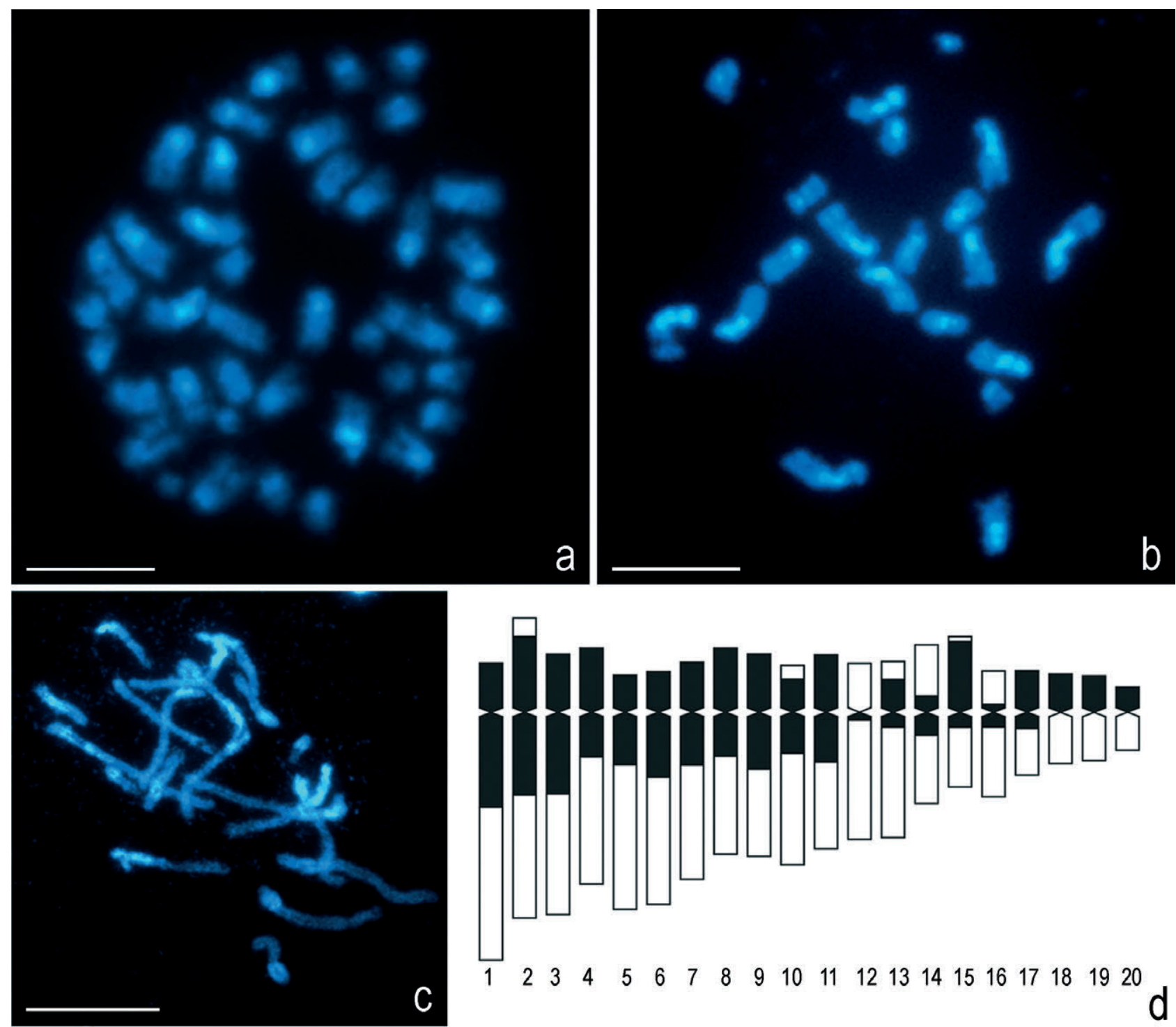

Fig. 2. Chromosome preparations obtained by spreading of cells from gonads of prepupal individuals, which have been C-banded and stained with DAPI (blue). $\mathrm{a}$ - female metaphase; $\mathrm{b}$ - male metaphase; $\mathrm{c}$ - female pachytene; $\mathrm{d}$ - ideogram of the male karyotype showing distribution of heterochromatin (black) and euchromatin (white). Bar $=5 \mu \mathrm{m}(\mathrm{a}-\mathrm{b}), 10 \mu \mathrm{m}(\mathrm{c})$.

CCD camera and Leica IM50 Software, version 4.0 (Leica Microsystems Imaging Solutions Ltd., Cambridge, UK). Blackand-white images were recorded, pseudo-coloured if necessary (light blue for DAPI and red for Cy3) and processed with appropriate software. Chromosome sizes, centromeric indexes and amount of heterochromatin and euchromatin were measured using the computer application MicroMeasure version 3.3 (available at http://www.colostate.edu/Depts/Biology/Micromeasure) (Reeves \& Tear, 2000). These data were used to describe the male karyotype according to Levan et al. (1964) and Hoshiba \& Imai (1993).

\section{RESULTS}

\section{Classical cytogenetic analysis}

Diachasmimorpha longicaudata possesses a female diploid chromosome complement of $2 \mathrm{n}=40$ chromosomes (Fig. 1a) and a male haploid chromosome number of $\mathrm{n}=20$ (Fig. 1b-c). The male karyotype consists of 15 metacentric-submetacentric chromosomes and five acro- centric chromosomes that gradually decrease in size, with the exception of chromosome 20 which is markedly smaller (Fig. 1b-c). The analysis of meiotic chromosome preparations shows the presence of positive heteropycnotic regions in one or both chromosome arms in the majority of the chromosomes, with the exception of chromosome 12 , which is entirely negatively heteropycnotic (Fig. 1b-c). An ideogram of the male metaphase chromosomes of this species is shown in Fig. 1d.

\section{C-banding}

All chromosomes from ovaries and testes showed $\mathrm{C}$-positive bands at the pericentromeric regions at metaphase (Fig. 2a-d). In 26 chromosomes of the diploid complement $(2 \mathrm{n}=40)$ (Fig. $2 \mathrm{a})$ and 13 chromosomes of the haploid complement $(n=20)$ (Fig. 2b), these bands covered the entire short arm. In addition, in 22 chromosomes of females (Fig. 2a) and 11 of males (Fig. 2b), the 

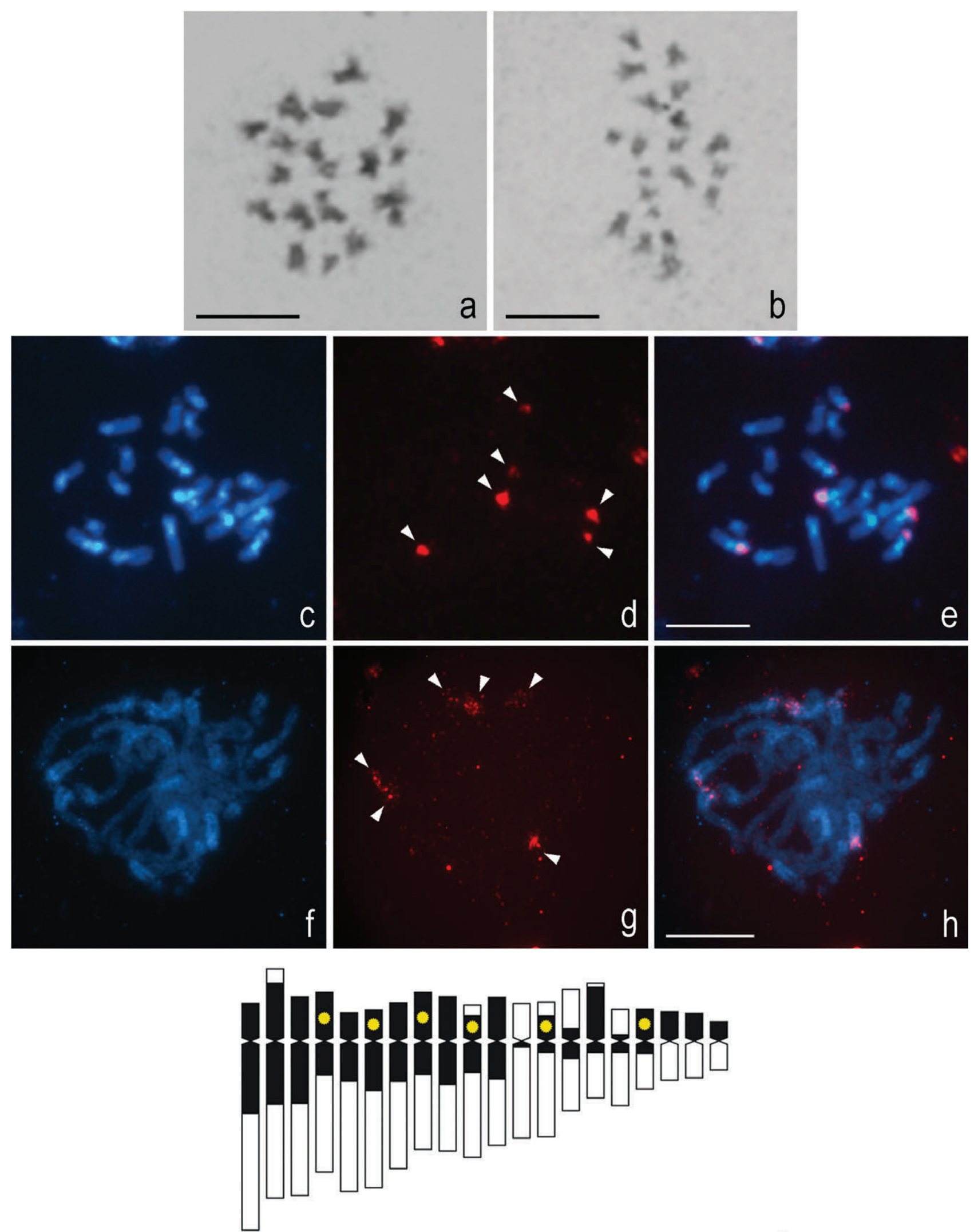

$\begin{array}{lllllllllllllllllllll}1 & 2 & 3 & 4 & 5 & 6 & 7 & 8 & 9 & 10 & 11 & 12 & 13 & 14 & 15 & 16 & 17 & 18 & 19 & 20\end{array}$

Fig. 3. Chromosome preparations obtained by spreading of cells from testes and ovaries of prepupal individuals, a-b - Ag-NOR stained; $\mathrm{c}-\mathrm{h}$ - stained with rDNA-FISH using 18S rDNA labelled probes (blue - DAPI counterstaining; red - hybridization signals). $\mathrm{c}, \mathrm{f}$ - DAPI-stained chromosomes; $\mathrm{d}, \mathrm{g}$ - Cy3 hybridization signals; $\mathrm{e}, \mathrm{h}$ - merged images. $\mathrm{a}-\mathrm{b}$ - male metaphases without clear Ag-NOR signals; $\mathrm{c}-\mathrm{e}$ - male metaphase; $\mathrm{f}-\mathrm{h}$ - female pachytene; $\mathrm{i}$ - ideogram of the male karyotype showing distribution of heterochromatin (black) and euchromatin (white) and location of hybridization signals (yellow circles). Arrowheads, hybridization signals. $\operatorname{Bar}=5 \mu \mathrm{m}(\mathrm{a}-\mathrm{b}, \mathrm{e}), 10 \mu \mathrm{m}(\mathrm{h})$. 
constitutive heterochromatin also occupied almost half of the long arm.

In oogonia, during pachytene, 20 bivalents were found and all of them had deeply stained pericentromeric heterochromatic regions (Fig. 2c). A total of 40.2\% $( \pm 2.1$, standard error) of the karyotype was composed of constitutive heterochromatin. An ideogram of the male metaphase chromosomes of this species including the proportion of each chromosome consisting of heterochromatin is shown in Fig. 2d. The karyotype of D. longicaudata males consists of ten metacentric-submetacentric chromosomes each with a heterochromatic short arm and pericentromeric heterochromatin, three pseudo-acrocentric chromosomes, two acrocentric-submetacentric chromosomes with euchromatic arms and five metacentricsubmetacentric chromosomes with pericentromeric heterochromatin.

\section{Ag-NOR staining}

No NORs could be accurately detected in male metaphases as all the Ag-NOR bands were coincident with C-positive bands (Fig. 3a, b). Nevertheless, one to three positive spots were identified in spermatids and spermatocytes (data not shown).

\section{Fluorescent in situ hybridization of rDNA}

FISH experiments with $18 \mathrm{~S}$ rDNA autologous probes revealed six clusters of rRNA genes in the male haploid chromosome complement (Fig. 3c-e). The hybridization signals were localized in the short heterochromatic arm of six meta-submetacentric chromosomes (Fig. 3e). These signals showed different intensities with two strong, two medium and two weak signals (Fig. 3d). Based on the length and morphology of the chromosomes bearing the hybridization spots, it was possible to identify and individualize them in the karyotype of this species (Fig. 3i). When females were analyzed at pachytene, the same number and location of rRNA genes were observed, although the signals were less obvious due to a lower condensation of the pachytene bivalents (Fig. $3 \mathrm{f}-\mathrm{h}$ ).

\section{DISCUSSION}

Currently, the karyotype of 170 species of the superfamily Ichneumonoidea have been described, including 110 species of the family Ichneumonidae and 60 of the family Braconidae (Gokhman, 2009). In this superfamily, the haploid chromosome number varies between 3 and 21 , with a modal number of $n=11$. The analysis of chromosome variation in parasitic wasps belonging to the Braconidae revealed that different chromosome numbers prevail in the three main phylogenetic branches of this group: (i) from 14 to 20 in cyclostome Braconidae (subfamilies Doryctinae, Opiinae and Alysiinae), (ii) from 3 to 9 in Aphidiinae (which is apparently a sister group of cyclostome Braconidae) and (iii) from 5 to 11 in most non-cyclostome Braconidae (subfamilies Meteorinae, Microgastrinae, Cheloninae, etc.) (Gokhman, 2004). Results of our cytogenetic analysis of Diachasmimorpha longicaudata (subfamily Opiinae) using the classical approach are consistent with the distribution detailed above and also confirm the chromosome number of $\mathrm{n}=$ 20 (male) $/ 2 \mathrm{n}=40$ chromosomes (female), previously reported by Kitthawee et al. (1999).

The presence of pericentromeric and telomeric heterochromatic segments is the most characteristic pattern in parasitic Hymenoptera. However, strong inter-specific differences in the size and location of heterochromatic segments were found in the families Ichneumonidae and Aphelinidae (Gokhman, 1997; Baldanza et al., 1999). With regards to Braconidae, only two species have been studied using C-banding: Apanteles sp. (Foerster) $(\mathrm{n}=$ 11) (Hoshiba \& Imai, 1993) and Aphidius ervi (Haliday) $(\mathrm{n}=5,2 \mathrm{n}=10-12)$ (Gokhman, 2003). In Apanteles sp., the karyotype is composed of one pseudoacrocentric chromosome (i.e., chromosomes with the short arm fully heterochromatic and long arm euchromatic), nine acrocentric - submetacentric chromosomes with interstitial heterochromatin and one metacentric chromosome with euchromatic arms (Hoshiba \& Imai, 1993). Whereas in $A$. ervi, an extra pair of fully heterochromatic acrocentric chromosomes is reported in several females, while no information is available on the distribution of heterochromatic content in the regular set of chromosomes (Gokhman, 2003). Our results obtained using C-banding in $D$. longicaudata revealed a much higher heterochromatic content when compared to the C-banded karyotype of the other two braconid species. Furthermore, the use of this technique resulted in a better and deeper characterization of the chromosomes of this species by revealing the presence of pseudoacrocentric chromosomes.

The differences between these three species of Braconidae revealed by $\mathrm{C}$-banding could be explained by the mechanisms proposed below as responsible for the quantitative variation in the distribution of the heterochromatin within and among species: multiple replication, unequal exchange, amplification and/or accumulation and elimination (reviewed in John, 1988). Taking into account these processes, the high content of heterochromatin in D. longicaudata could result from amplification of pre-existent heterochromatin or the addition of new heterochromatin at interstitial and/or pericentromeric positions. However, molecular mechanisms involved in the karyotype differentiation of $D$. longicaudata by heterochromatin amplification remain to be elucidated.

Concerning the location of rDNA within Braconidae, only one species has been studied using FISH, Cotesia congregata (Belle et al., 2002), and none using Ag-NOR staining (Gokhman, 2009). In C. congregata, one and two hybridization signals were identified in male and female cells, respectively, using a heterologous rDNA probe. These signals were located on the short arm of the smallest subtelocentric chromosome pair (Belle et al., 2002). In the present work, FISH revealed six clusters of rDNA per haploid genome, located on the short heterochromatic arm of the six meta-submetacentric chromosomes of D. longicaudata. It is worth noticing that these studies represent the first use of an autologous probe for rDNA-FISH in a species of Braconidae. In some species of Hymenoptera, the rRNA genes are confined to a single 
site on a pair of homologous chromosomes, but a high number of rDNA sites is not unusual as the rDNA often spreads over several chromosomes during karyotype evolution, resulting in inter-specific variation in the number of NORs (Sumner, 1990; Hirai et al., 1994). Thus, $C$. congregata and D. longicaudata are examples of this variability within Braconidae.

Most NORs in eukaryotes are located in regions particularly rich in heterochromatin (Goessens, 1984; Hadjiolov, 1985; Babu \& Verma, 1987), probably because the structures associated with heterochromatin can be used to silence some repetitions and avoid recombination between them (Gottlieb \& Esposito, 1989). Nonetheless, the rDNA has an important propensity for self duplication and accretions (Rousselet et al., 1998). As rRNA is needed in huge quantities in eukaryotic cells, the amplification of rDNA seems to be an evolutionary adaptation (Long \& Dawid, 1980). When rDNA-FISH is applied, differences in the intensity of the hybridization signals reflect differences in the number of repetitions of rDNA (Appels et al., 1980; Wachtler et al., 1986; Leitch \& Heslop-Harrison, 1992). In D. longicaudata, all the rDNA loci are located on heterochromatic short arms and the hybridization signals vary in intensity. Thus, it is likely that in this species the rDNA loci differ quantitatively in the number of repetitions.

The analysis of NORs using silver impregnation of metaphase chromosomes of D. longicaudata did not allow the identification of the functional rDNA loci, as the locations of the Ag-NOR and C-positive bands are coincident. This may be due to the stainability with silver of proteins rich in acidic residues in regions free of rDNA, which is extensively reported (Palomeque et al., 1988; Sumner, 1990; Sánchez et al., 1995; Hirai et al., 1996; Vitturi et al., 1999; Dobigny et al., 2002; Colomba et al., 2004). Nevertheless, there were from one to three conspicuous Ag-NOR signals in spermatocytes and spermatids of $D$. longicaudata. These results agree with previous studies on several species of Hymenoptera, where multiple loci of rDNA are detected by FISH in the haploid chromosome complement but only one is usually active (Hirai et al., 1994; Matsumoto et al., 2002; Gokhman, 2009). However, it is worth mentioning that the fusion of nucleoli in interphase nuclei is a phenomenon commonly referred to in plants, animals and man (e.g., Bombarová et al., 2007, and references therein). This means that it is not possible to obtain an accurate estimate of the number of active NORs in D. longicaudata without a detailed analysis of mitotic and/or meiotic chromosomes in the prophase to metaphase stages.

Increase in chromosome number by centric fission is considered to be an evolutionary adaptation to minimize deleterious chromosomal interactions (Hirai et al., 1994). However, unstable telomeres are generated after this kind of rearrangement. These naked chromosome ends are ultimately sealed by (i) a new telomere generated de novo by telomerase (Blackburn, 1991; Werner et al., 1992; Greider et al., 1993; Richards et al., 1993), (ii) the presence of telomeric sequences in the centromere region of the ancestral chromosome (Hall \& Parker, 1995), or (iii) an increase in the amount of constitutive heterochromatin (Hirai et al., 1994) through tandem gene duplication or saltatory replication (Britten \& Kohne, 1969). The last case leads to the generation of pseudoacrocentric chromosomes. Furthermore, constitutive heterochromatic blocks or rDNA clusters might constitute fragile sites and represent preferential breakage points for various chromosomal rearrangements, such as fissions (Hall \& Parker, 1995; Cerbah, 1997). It is possible that the presence of repeated DNA sequences at or close to the breaking point stabilize chromosomes after fission (Hall \& Parker, 1995; Cerbah, 1997). However, the excess of constitutive heterochromatin has to be eliminated eventually, since its unspecific associations may lead to deleterious interactions. This elimination occurs mainly by means of a pericentric inversion of acrocentric chromosomes and partly by centric fusions, leading to the alteration of chromosome morphology by again generating metacentric chromosomes. These processes do not necessarily affect the amount and distribution of rDNA loci (Hirai et al., 1994). Hence, the high content of heterochromatin described in D. longicaudata along with the presence of pseudoacrocentric chromosomes, the high number of rDNA loci located in heterochromatic regions, the predominantly submetacentric morphology and the two modal chromosome numbers in Braconidae, allow us to hypothesize that centric fissions might have played a significant role in the karyotype evolution of D. longicaudata and its chromosome complement might be in an intermediate state of differentiation

ACKNOWLEDGEMENTS. This work was funded by grants UBACyT X164 and W917 of University of Buenos Aires, PIP 0281 of Consejo Nacional de Investigaciones Científicas y Técnicas (CONICET), PICT 2007-00635 and PICT 2008-0502 of ANPCyT. L.Z. Carabajal Paladino, M.J. Bressa and A.G. Papeschi acknowledge support from CONICET. S.B. Lanzavecchia and J.L. Cladera acknowledge support from INTA. We wish to thank M.G. Poggio, M. Chirino, C. Giardini and C. Conte for their help.

\section{REFERENCES}

AвE Y. 1994: The karyotype of the chestnut gall wasps Dryocosmus kuriphilus (Hymenoptera, Cynipidae). - Appl. Entomol. Zool. 29: 299-300.

Appels R., Gerlachi W., Dennis L., Swift S. \& Peacock W. 1980: Molecular and chromosomal organization of DNA sequences coding for the ribosomal RNAs in cereals. - Chromosoma 78: 293-311.

BABU K. \& Verma R. 1987: Chromosome structure: Euchromatin and heterochromatin. - Int. Rev. Cytol. 108: 1-60.

BALDANZA F. \& GIORGINI M. 2001: Karyotype and NOR localization differences between Encarsia formosa Gahan and Encarsia luteola Howard (Hymenoptera: Aphelinidae). Boll. Lab. Agr. Filippo Silvestri 56: 33-41.

Baldanza F., Gaudio L. \& Viggiani G. 1999: Cytotaxonomic studies of Encarsia Foerster (Hymenoptera: Aphelinidae). - Bull. Entomol. Res. 89: 209-215.

Bombarová M., Marec F., Nguyen P. \& Spakulova M. 2007: Divergent location of ribosomal genes in chromosomes of fish thorny-headed worms, Pomphorhynchus laevis and Pom- 
phorhynchus tereticollis (Acanthocephala). - Genetica 131: 141-149.

Baruffi L., Damiani G., Guglielmino C., Bandi C., Malacrida A. \& Gasperi G. 1995: Polymorphism within and between population of Ceratitis capitata. Comparison between RAPD and Multilocus enzyme electrophoresis data. - Heredity 74: 524-537.

Belle E., Beckage N., Rousselet J., Poirié M., Lemeunier F. \& DREZEN J. 2002: Visualization of polydnavirus sequences in a parasitoid wasp chromosome. - J. Virol. 76: 5793-5796.

Bernardo U., Monti M.M., Nappo A.G., Gebiola M., Russo A., Pedata A.A. \& Viggiani G. 2008: Species status of two populations of Pnigalio soemius (Hymenoptera: Eulophidae) reared from two different hosts: An integrative approach. Biol. Contr. 46: 293-303.

Blackburn E. 1991: Structure and function of telomeres. Nature 350: $569-573$.

Bressa M., Papeschi A., Vítková M., KubíčKová S., Fuková I., Pigozzi M. \& Marec F. 2009: Sex chromosome evolution in cotton stainers of the genus Dysdercus (Heteroptera: Pyrrhocoridae). - Cytogenet. Genome Res. 125: 292-305.

BRITTEN R. \& KoHNE D. 1969: Handbook of Molecular Cytology. North-Holland Publication, Amsterdam, 2236 pp.

Carabajal Paladino L.Z., Papeschi A.G. \& Cladera J.L. 2010: Immature stages of development in the parasitoid wasp Diachasmimorpha longicaudata. - J. Insect Sci. 10.56.

CERBAH M. 1997: Hétérochromatine, organisateurs nucléolaires et evolution du genome chez quelques espèces végétales: cas particulier du genre Hypochaeris. PhD Thesis, University of Orsay, $55 \mathrm{pp}$.

Colomba M.S., Vitturi R., Volpe N., Lannino A. \& Zunino M. 2004: Karyotype, banding and rDNA FISH in the scarab beetle Anoplotrupes stercorosus (Coleoptera: Scarabaeoidea: Geotrupidae). Description and comparative analysis. Micron 35: 717-720.

Crozier R. 1975: Hymenoptera. In John B. (ed.): Animal Cytogenetics. Vol. 7. Borntraeger, Berlin, vi $+95 \mathrm{pp}$.

De Menten L., Niculita H., Gilbert M., Delnest D. \& Aron S. 2003: Flourescence in situ hybridization: a new method for determining primary sex ratio in ants. - Mol. Ecol. 12: $1637-1648$

Dobigny G., Ozouf-Costaz C., Bonillo C. \& Volobouev V. 2002: "Ag-NORs" are not always true NORs: new evidence in mammals. - Cytogenet. Genome Res. 98: 75-77.

Fuková I., NGuyen P. \& Marec F. 2005: Codling moth cytogenetics: karyotype, chromosomal location of rDNA, and molecular differentiation of sex chromosomes. - Genome 48: 1083-1092.

Giorgini M. \& Baldanza F. 2004: Species status of two populations of Encarsia sophia (Girault et Dodd) (Hymenoptera: Aphelinidae) native to different geographic areas. - Biol. Contr. 30: 25-35.

Glaser R.W. 1917: Ringer solutions and some notes on the physiological basis of their ionic composition. - Comp. Biochem. Physiol. 2: 241-289.

Godfray H. 1994: Parasitoids: Behavioural and Evolutionary Ecology. Princeton University Press, New Jersey, 473 pp.

Goessens G. 1984: Nucleolar structure. - Int. Rev. Cytol. 84: $107-158$

GoKhman V.E. 1985: Chromosome sets of some Ichneumons from the subfamily Ichneumoninae (Hymenoptera, Ichneumonidae). - Zool. Zh. 64: 1409-1413.

Gokhman V.E. 1997: Chromosome number and other karyotypic features of parasitic wasps as a source of taxonomic information. - Bol. Asoc. Esp. Entomol. (Supl.) 21: 53-60.
GoKHMAN V.E. 2000a: Karyology of parasitic Hymenoptera: current state and perspectives. In Austin A. \& Dowton M. (eds): Hymenoptera. Evolution, Biodiversity and Biological control. CSIRO Publishing, Collingwood, pp. 198-206.

GoKHMAn V.E. 2000b: The karyotype of Anaphes iole (Hymenoptera, Mymaridae) and the evolution of chromosome numbers in the superfamily Chalcidoidea. - Zool. Zh. 79: $1485-1487$.

GoKhman V.E. 2001: Chromosomes of Ichneumons from the family Ichneumonidae (Hymenoptera). - Zool. Zh. 80: 968-975.

GoKHMAN V.E. 2002: Karyotype evolution and the role of chromosome analysis in the taxonomy of parasitic Hymenoptera. - Proc. XII Congress of Russian Entomological Society, St. Petersburg, 19-24 August 2002. Abstracts. St. Petersburg, p. 87. [in Russian].

GoKhman V.E. 2003: Karyotypes of Parasitic Hymenoptera: Evolution and the Role in Systematics and Phylogeny. PhD thesis, Moscow State University, 338 pp. [in Russian].

GoKHMAN V.E. 2004: Karyotype evolution in parasitic Hymenoptera. - Entomol. Rev. 84: S161-S169.

GoKHMAN V.E. 2005: New chromosome records for the superfamily Chalcidoidea (Hymenoptera). - Cytologia 70: 239-241.

GoKHMAN V.E. 2006: Karyotype of parasitic Hymenoptera: Diversity, evolution and taxonomic significance. - Insect Sci. 13: 237-241.

GoKHMAn V.E. 2009: Karyotypes of the Parasitic Hymenoptera. Springer, London, xiv $+186 \mathrm{pp}$.

Gottlieb S. \& Esposito R. 1989: A new role for a yeast transcriptional silencer gene, SIR2, in regulation of recombination in ribosomal DNA. - Cell 56: 771-776.

GoKHMAn V.E. \& Quicke D.L.J. 1995: The last twenty years of parasitic Hymenoptera karyology: an update and phylogenetic implications. - J. Hymenopt. Res. 4: 41-63.

GoKHMAN V.E. \& WestendorfF M. 2000: The chromosomes of three species of the Nasonia complex (Hymenoptera, Pteromalidae). - Beitr. Entomol. 50: 193-198.

GokHMAn V.E. \& WestendorfF M. 2003: Chromosomes of Aphidius ervi Haliday, 1834 (Hymenoptera, Braconidae). - Beitr. Entomol. 53: 161-165.

Greider C., Autexier C., Avilion A., Collins K., Harrington L., Mantell L., Prowse K.R., Smith S.K., Allsopp R.C., Counter C.M., Vaziri H., Bacchetti S. \& Harley C.B. 1993: Telomeres and telomerase: biochemistry and regulation in senescence and immortalization. In Heslop-Harrison J. \& Flavell R. (eds): The Chromosome. Bios Scientific Publisher, Oxford, pp. 115-125.

Guerra M. 1999: Hematoxylin: a simple, multiple-use dye for chromosome analysis. - Genet. Mol. Biol. 22: 77-80.

HadJiolov A. 1985: The Nucleolus and Ribosome Biogenesis. Springer, Vienna, $268 \mathrm{pp}$.

HALL K. \& PARKER J. 1995: Stable chromosome fission associated with rDNA mobility. - Chromosome Res. 3: 417-422.

Hirai H., Yamamoto M.-T., Ogura K., Satta Y., Yamada M., TAYLOR R. \& IMAI H. 1994: Multiplication of 28S rDNA and NOR activity in chromosome evolution among ants of the Myrmecia pilosula species complex. - Chromosoma 103: 171-178.

Hirai H., Yamamoto M.-T., Taylor R. \& Imai H. 1996: Genomic dispersion of $28 \mathrm{~S}$ rDNA during karyotypic evolution in the ant genus Myrmecia (Formicidae). - Chromosoma 105: 190-196.

Hoshiba H. \& Imai H. 1993: Chromosome evolution of bees and wasps (Hymenoptera, Apocrita) on the basis of C-banding pattern analyses. - Jap. J. Entomol. 61: 465-492. 
Hung A.C.F. 1986: Chromosomes of three Brachymeria species (Hymenoptera: Chalcidoidea). - Experientia 42: 579-580.

imai H., Taylor R., Crosland M. \& Crozier R. 1988: Modes of spontaneous chromosomal mutation and karyotype evolution in ants with reference to the minimun interaction hypothesis. — Jap. J. Genet. 63: 159-185.

JoHN B. 1988: The biology of heterochromatin. In Verma R.S (ed.): Heterochromatin: Molecular and Structural Aspects. Cambridge University Press, Cambridge, pp. 1-147.

Kitthawee S., Singhapong S. \& Baimai V. 1999: Metaphase chromosomes of parasitic wasps Diachasmimorpha longicaudata (Hymenoptera: Braconidae) in Thailand. - Cytologia 64: 111-115.

Kitthawee S., Singhapong S. \& Baimai V. 2004: Karyotypes of five species of tephritid fruit fly parasitoid (Hymenoptera: Braconidae) from Thailand. - Caryologia 57: 133-137.

Leitch I.J. \& Heslop-Harrison J.S. 1992: Physical mapping of the $18 S-5,8 S-26 S$ rDNA genes in barley by in situ hybridization. - Genome 35: 1013-1018.

Levan A., Fredga K. \& Sandberg A. 1964: Nomenclature for centromeric position on chromosomes. - Hereditas 52: 201-220.

Lockwood A.P.M. 1961: 'Ringer' solutions and some notes on the physiological basis of their ionic composition. - Comp. Biochem. Physiol. 2: 241-289.

LoNG E. \& DAwID I. 1980: Repeated genes in eukaryotes. - Annu. Rev. Biochem. 49: 727-764.

Maffei E.M.D, Pompolo S.G., De Oliveira Campos L.A. \& PetiTIPIERRE E. 2001: Sequential FISH analysis with rDNA genes and Ag-NOR banding in the lady beetle Olla v-nigrum (Coleoptera: Coccinellidae). - Hereditas 135: 13-18.

MaruCCI P.E. \& Clancy D.W. 1950: The artificial culture of fruit flies and their parasites. - Proc. Hawaii. Entomol. Soc. 14: $163-166$.

Matsumoto K., Yamamoto D.S., Sumitani M., Lee J.M., HataKeYAMA M. \& Oishi K. 2002: Detection of single copy gene on a mitotic methaphase chromosome by flourescent in situ hybridization (FISH) in the sawfly Athalia rosae. - Arch. Insect Biochem. Physiol. 41: 34-40.

Palomeque T., Chica E., Cano M. \& Díaz de la Guardia R. 1988: Karyotypes, C-banding and chromosomal location of active nucleolar organizing regions in Tapinoma (Hymenoptera, Formicidae). - Genome 30: 277-280.

PAPESCH A.G. 1988: C-banding and DNA content in three species of Belostoma (Heteroptera) with large differences in chromosome size and number. - Genetica 76: 43-51.

Quicke D. 1997: Parasitic Wasps. Chapman and Hall, London, $470 \mathrm{pp}$.

RASNITSYN A. 1980: The origin and evolution of Hymenoptera. - Tr. Paleontol. Inst. Akad. Nauk SSSR 174: 1-192.

REED K. 1993: Cytogenetic analysis of the paternal sex ratio chromosome of Nasonia vitripennis. - Genome 36: 157-161.

ReEves A. \& TEAR J. 2000: MicroMeasure for Windows, version 3.3. (Free program, distributed by the authors via http://www.colostate.edu/Depts/Biology/Micro-Measure).
Richards E., Vongs A., Walsh M., Yang J. \& Chao S. 1993: Substructure of telomere repeat arrays. In Heslop-Harrison J. \& Flavell R. (eds): The Chromosome. Bios Scientific Publisher, Oxford, pp. 115-125.

Rousselet J., Géri C., Hewitt G. \& Lemeunier F. 1998: The chromosomes of Diprion pini and D. similis (Hym.: Diprionidae): implications for karyotype evolution. - Heredity 81: 573-578.

Sahara K., Marec F. \& Traut W. 1999: TTAGG telomeric repeats in chromosomes of some insects and other arthropods. - Chromosome Res. 7: 449-460.

SÁnchez A., Jiménez R., Burgos M., Stitou S., Zurita F. \& de LA Guardia R.D. 1995: Cytogenetic peculiarities in the Algerian hedgehog: silver stains not only NORs but also heterochromatic blocks. - Heredity 75: 10-16.

SIVINSKI J. 1996: The past and potential of biological control of fruit flies. In McPheron B.A. \& Steck G.J. (eds): Fruit Fly Pests: A World Assessment of their Biology and Management. St. Lucie Press, Del Ray Beach, FL, pp. 365-375.

Stack S., Herickhoff L., Sherman J. \& Anderson L. 1991: Staining plant cells with silver. I. The salt-nylon technique. - Biotech. Histochem. 66: 69-78.

Stebbins G.L. 1950: Variation and Evolution in Plants. Columbia University Press, New York, 643 pp.

Stoltz D. \& Whitfield J. 1992: Viruses and virus-like entities in the parasitic Hymenoptera. - J. Hymenopt. Res. 1: $125-139$.

Sumner A.T. 1990: Chromosome Banding. Unwin Hyman, London, $434 \mathrm{pp}$.

Traut W. 1976: Pachytene mapping in the female silkworm Bombyx mori L. (Lepidoptera). - Chromosoma 58: 275-284.

Van Vugt J.J.F.A., De Jong H. \& Stouthamer R. 2009: The origin of a selfish $\mathrm{B}$ chromosome triggering paternal sex ratio in the parasitoid wasp Trichogramma kaykai. - Proc. R. Soc. (B) 276: 4149-4154.

ViKtorov G. 1976: The Ecology of Entomophagous Parasites. Nauka, Moscow, 152 pp. [in Russian].

Vitturi R., Colomba M.S., Barbieri R. \& Zunino M. 1999: Ribosomal DNA location in the scarab beetle Thorectes intermedius (Costa) (Coleptera: Geotrupidae) using banding and fluorecent in situ hybridization. - Chromosome Res. 7: 255-260.

Wachtler F., Hopman A.H., Wiegant J. \& Schwarzacher H.G. 1986: On the position of nucleolus organizer regions (NORs) in interphase nuclei. Studies with a new non-autoradiographic in situ hybridization method. - Exp. Cell Res. 167: 227-240.

Werner J., Kota R. \& Gill B. 1992: Distribution of telomeric repeats and their role in the healing of broken chromosome ends in wheat. - Genome 35: 844-848.

Whiting P. \& Whiting A. 1925: Diploid males from fertilized eggs in Hymenoptera. - Science 62: 437-438.

Received August 3, 2012; revised and accepted January 2, 2013 